Зиганшин М.M.

\title{
АДМИНИСТРАТИВНО-ПРАВОВОЙ СТАТУС ИНОСТРАННЫХ ГРАЖДАН И ЛИЦ БЕЗ ГРАЖДАНСТВА (АПАТРИДЫ) - УЧАСТНИКОВ ДОРОЖНОГО ДВИЖЕНИЯ
}

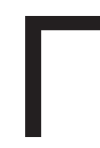

осударственная политика в области обеспечения безопасности является частью внутренней и внешней политики Российской Федерации и представляет собой совокупность скоординированных и объединенных единым замыслом политических, организационных, социальноэкономических, военных, правовых, информационных, специальных и иных мер.

Государственная политика в области обеспечения безопасности реализуется федеральными органами государственной власти, органами государственной власти субъектов Российской Федерации, органами местного самоуправления на основе стратегии национальной безопасности Российской Федерации, иных концептуальных и доктринальных документов, разрабатываемых Советом Безопасности и утверждаемых Президентом Российской Федерации.

Граждане и общественные объединения участвуют в реализации государственной политики в области обеспечения безопасности.

М.В. Костенников, исследуя правовое регулирование транспортной безопасности и роль полиции в ее обеспечении, пишет: «говоря о безопасности транспорта и транспортной инфрраструктуры то необходимо отметить, что безопасность - состояние защищенности жизненно важных интересов личности, общества и государства от внешних и внутренних угроз. Такое понятие безопасности является общим для всех видов безопасности. Но для каждого вида общественной безопасности существует специальный административно-правовой режим ее обеспечения» ${ }^{[1]}$.

Существуют различные виды безопасности: военная безопасность, геологическая безопасность, космическая безопасность, пожарная безопасность, финансовая безопасность, информационная безопасность, транспортная безопасность и т.д.

Один из аспектов транспортной безопасности мы предлагаем рассмотреть в данной статье.

Следует отметить, что в связи с произошедшими транспортными катастрофрами за последнее десятилетие правовое регулирование этой области получило стремительное развитие, в первую очередь связанно оно с принятием Федерального закона от 9 февраля 2007 года № 16-Ф3 «О транспортной безопасности», отраслевых приказов Минтранса России о требованиях по обеспечению транспортной безопасности, а также иных других правовых актов.

Целями обеспечения транспортной безопасности являются устойчивое и безопасное функционирование транспортного комплекса, защита интересов личности, общества и государства в сорере транспортного комплекса от актов незаконного вмешательства. Основными задачами обеспечения транспортной безопасности являются: нормативное правовое регулирование в области обеспечения транспортной безопасности; определение угроз совершения ак-

\footnotetext{
${ }^{1}$ Костенников М. В., Куракин А. В. Актуальные проблемы административного права. - М., 2013.
} 
тов незаконного вмешательства; оценка уязвимости объектов транспортной инфрраструктуры и транспортных средств; категорирование объектов транспортной инфраструктуры и транспортных средств; разработка и реализация требований по обеспечению транспортной безопасности; разработка и реализация мер по обеспечению транспортной безопасности; подготовка специалистов в области обеспечения транспортной безопасности; осуществление контроля и надзора в области обеспечения транспортной безопасности; информационное, материально-техническое и научнотехническое обеспечение транспортной безопасности.

Областью транспортной безопасности являются: безопасность воздушного движения (авиационная безопасность); безопасность движения на железнодорожном транспорте; безопасность на водном транспорте; автомобильная безопасность (безопасность, связанная с дорожным движением).

Обеспечение транспортной безопасности в каждого области определяется своими нормативными правовыми актами Российской Федерации. Безопасность воздушного движения (авиационная безопасность) - «Воздушным кодексом Российской Федерации» от 19 марта 1997 г. № 60-Ф3; безопасность движения на железнодорожном транспорте - Федеральным законом от 10 января 2003 г. № 17-Ф3 «О железнодорожном транспорте в Российской Федерации»; безопасность на водном транспорте «Кодексом внутреннего водного транспорта Российской Федерации» от 7 марта 2001 г. № 24-Ф3; автомобильная безопасность (безопасность, связанная с дорожным движением - Федеральным законом от 10 декабря 1995 г. № 196-Ф3 «О безопасности дорожного движения», постановлением Совета Министров Правительства Российской Федерации от 23 октября 1993 г. № 1090 «О правилах дорожного движения».

Транспортная система является одной из важнейших отраслей народного хозяйства, она выполняет функцию своеобразной кровеносной системы в сложном организме страны. Являясь составной и исключительно важной частью инфраструктуры России, транспортный комплекс обеспечивает не только внутренние межотраслевые связи и потребности населения в перевозках, но и позволяет осуществлять доставку пассажиров и экспортно-импортных грузов различного назначения в интересах развития международного культурного и технического сотрудничества, а также интеграцию России в мировую экономику.

В данной статье нам хотелось бы рассмотреть административно-правовой статус иностранных граждан и лиц без гражданства - как участников дорожного движения в области транспортной безопасности.

Из-за масштабов наносимого вреда аварийность отнесена $\mathrm{OOH}^{[2]}$ к основным угрозам современности. ООН призвала остановить и повернуть вспять тенденцию к росту числа смертельных случаев и травм в результате ДТП во всем мире.

Обстановка на дорогах России представляет реальную опасность демографии и национальной безопасности государства.

В 2013 году на территории России зарегистрировано 204068 дорожно-транспортных происшествий, в которых погибли 27025 и ранено 258437 человек и это притом, что наша страна сейчас переживает, без преувеличения, бум автомобилизации, в 2013 году зарегистрировано

\footnotetext{
${ }^{2}$ Из послания Генерального секретаря ООН Пан Ги Муна по случаю начала "Десятилетия действий по обеспечению безопасности дорожного движения 2011-2020гг.», на 64-й сессии генеральной ассамблеей ООН.
} 
53321510 единиц транспортных средств (в 2012 г. - 50512132 единиц) ${ }^{[3]}$.

Количество дорожно-транспортных происшествий напрямую связано с такими обстоятельствами как качество подготовки и воспитания водительских кадров, конструкция и техническое состояние транспортных средств, содержание улиц и дорог, их обустройство, но и немаловажным моментом является дисциплина участников дорожного движения.

В Федеральном законе "О транспортной безопасности» под субъектами транспортной инфраструктуры понимаются - юридические и фризические лица, являющиеся собственниками объектов транспортной инфрраструктуры и транспортных средств или использующие их на ином законном основание. То есть из выше озвученного следует, что иностранные граждане и лица без гражданства на территории Российской Федерации, являясь субъектами транспортной инфраструктуры, являются и участниками дорожного движения.

Согласно правилам дорожного движения участником дорожного движения является лицо, принимающее непосредственное участие в процессе движения в качестве водителя, пешехода, пассажира транспортного средства.

Сегодня наше государство, как и раньше, представляет интерес для иностранных граждан (трудовых мигрантов) как страна с высоким потенциалом спроса на рабочую силу. Достаточно большой сегмент среди востребуемых трудовых профессий занимают вакансии водителей грузового и легкового транспорта, автобусов, маршрутных такси и т.д.

Административно-правовой статус иностранных граждан и лиц без гражданства в Российской Федерации определяется в первую очередь Конституцией Российской Федерации, в частности

${ }^{3}$ Сайт http://www.gibdd.ru. (Дата обращения 14.11.2014 г.). статьями 27, 62, 63; международными договорами Российской Федерации; Федеральным законом от 25 июля 2002 г. № 115-Ф3 «О правовом положении иностранных граждан в Российской Федерации»; Федеральным законом от 18 июля 2006 г. № 109-Ф3 «О миграционном учете иностранных граждан и лиц без гражданства в Российской Федерации»; постановлениями Правительства Российской Федерации и иными нормативно-правовыми актами.

Административно-правовой статус иностранных граждан и лиц без гражданства представляет собой совокупность их прав и обязанностей, закрепленных нормами права и гарантированных государством.

Иностранный гражданин - фризическое лицо, не являющееся гражданином Российской Федерации и имеющее доказательства наличия гражданства (подданства) иностранного государства. Лицом без гражданства (апатридом) признается физическое лицо, не являющееся гражданином Российской Федерации и не имеющее доказательства наличия гражданства (подданства) иностранного государства.

Федеральный закон «О правовом положении иностранных граждан в Российской Федерации» определяет три правовых режима пребывания иностранных граждан и лиц без гражданства в нашей стране: временное пребывание; временное проживание; постоянное проживание. У каждой из категорий иностранных граждан имеются некоторые особенности правового положения. В соответствии с этими режимами различается и перечень документов, необходимых для подтверждения законности их пребывания на территории Российской Федерации.

В соответствии с Федеральным законом «О правовом положении иностранных граждан в Российской Федерации» 
документом, удостоверяющим личность иностранного гражданина в Российской Федерации, является паспорт иностранного гражданина либо иной документ, установленный Федеральным законом или признаваемый в соответствии с международным договором Российской Федерации в качестве документа, удостоверяющего личность иностранного гражданина. Документами, удостоверяющими личность лица без гражданства в Российской Федерации, являются: документ, выданный иностранным государством и признаваемый в соответствии с международным договором Российской Федерации в качестве документа, удостоверяющего личность лица без гражданства; разрешение на временное проживание; вид на жительство; иные документы, предусмотренные Федеральным законом или признаваемые в соответствии с международным договором Российской Федерации в качестве документов, удостоверяющих личность лица без гражданства.

Иностранные граждане допускаются к управлению транспортными средствами на территории Российской Федерации, но при этом должны иметь при себе:

международное водительское удостоверение при условии, если оно предъявляется вместе с национальным водительским удостоверением; национальное водительское удостоверение, выданное в иностранном государстве, не являющемся совместно с Российской Федерацией участником международных договоров в области обеспечения безопасности дорожного движения, признается действительным для управления транспортными средствами на территории Российской Федерации на основе взаимности при условии, если оно предъявляется вместе с заверенным в установленном порядке переводом на русский язык, за исключением случаев, если в данном водительском удостове- рении все записи произведены или дублируются буквами, совпадающими по написанию с буквами русского или латинского алфавита.

Иностранные национальные и международные водительские удостоверения признаются действительными для управления транспортными средствами на территории Российской Федерации по достижении владельцами указанных водительских удостоверений возраста, предусмотренного статьей 26 Федерального закона «О безопасности дорожного движения» для соответствующих категорий и подкатегорий транспортных средств; регистрационные документы на транспортное средство; страховой полис обязательного страхования гражданской ответственности владельца транспортного средства в случаях; документы, предусмотренные таможенным законодательством Таможенного союза, с отметками таможенных органов, подтверждающими временный ввоз данного транспортного средства (при наличии прицепа - и прицепа); разрешение и другие документы, которые в соответствии с международными соглашениями и договорами Российской Федерации в области международного автомобильного сообщения требуются для осуществления международных автомобильных перевозок.

Тенденцией последнего времени становится более жесткий контроль за деятельностью многочисленных иностранных граждан и лиц без гражданства, которые приезжают в Российскую Федерацию на длительный срок. Свое отражение это нашло и в законодательстве, касающемся управления автомобилем иностранными гражданами.

Федеральным законом от 7 мая 2013 г. № 92-Ф3 «О внесении изменений в Федеральный закон «О безопасности дорожного движения» и «Кодекс Российской Федерации об административных 
правонарушениях» внесены изменения. В Федеральный закон «О безопасности дорожного движения»:

- в статью 20 п. 2 «Юридическим лицам и индивидуальным предпринимателям запрещается: допускать к управлению транспортными средствами водителей, не имеющих российских национальных водительских удостоверений»;

- в статью 25:

- п.13 «Не допускается управление транспортными средствами на основании иностранных национальных или международных водительских удостоверений при осуществлении предпринимательской и трудовой деятельности, непосредственно связанной с управлением транспортными средствами»;

- п.14. «Лица, не являющиеся гражданами Российской Федерации, допускаются к управлению транспортными средствами на территории Российской Федерации на основании международного водительского удостоверения при условии, если оно предъявляется вместе с национальным водительским удостоверением»;

- п.15. «Иностранное национальное водительское удостоверение, признается действительным для управления транспортными средствами на территории Российской Федерации, если оно предъявляется вместе с заверенным в установленном порядке переводом на русский язык, за исключением случаев, если в данном водительском удостоверении все записи произведены или дублируются буквами, совпадающими по написанию с буквами русского или латинского алфравита»;

- п.16. «Иностранные национальные и международные водительские удостоверения признаются действительными для управления транспортными средствами на территории Российской Федерации по достижении владельцами указанных водительских удостоверений возраста»;
- п.18. «Порядок обмена иностранных национальных и международных водительских удостоверений на российские национальные и международные водительские удостоверения устанавливается Правительством Российской Федерации».

Также, глава 12 Федерального закона от 30 декабря 2001 г. № 195-Ф3 «Кодекс Российской Федерации об административных правонарушениях» дополнена статьей 12.321: Допуск к управлению транспортным средством водителя, не имеющего в случаях, предусмотренных законодательством Российской Федерации о безопасности дорожного движения, российского национального водительского удостоверения или временного разрешения на право управления транспортными средствами, - влечет наложение административного штрафа на должностных лиц, ответственных за техническое состояние и эксплуатацию транспортных средств, в размере пятидесяти тысяч рублей.

В соответствии с Федеральным законом от 5 мая 2014 г. № 132-Ф3 «О внесении изменений в статью 3 Федерального закона "О внесении изменений в Федеральный закон «О безопасности дорожного движения» и «Кодекс Российской Федерации об административных правонарушениях» отложен срок введения запрета управлять транспортным средством (занимаясь предпринимательской и трудовой деятельностью) на основании иностранных национальных или международных водительских удостоверений. Дата вступления в силу указанного запрета перенесена с 7 мая 2014 г. на 1 июня 2015 г.

Дело в том, что порядок обмена иностранных национальных и международных водительских удостоверений на российские национальные и международные водительские удостоверения устанавливается Правительством Рос- 


\section{Полицейская деятельность 6 • 2014}

сийской Федерации. Так, в соответствии со статьей 25 Федерального закона «О безопасности дорожного движения» Правительство Российской Федерации постановлением Правительства Российской Федерации от 24 октября 2014 г. № 1097 «О допуске к управлению транспортными средствами» утвердило «Правила проведения экзаменов на право управления транспортными средствами и выдачи водительских удостоверений». Министерству внутренних дел Российской Федерации в 4-месячный срок утвердить административный регламент по предоставлению государственной услуги по проведению экзаменов на право управления транспортными средствами и выдаче водительских удостоверений.

В главе IV «Правил проведения экзаменов на право управления транспортными средствами и выдачи водительских удостоверений» расписан порядок обмена иностранных водительских удостоверений. Обмен иностранного национального водительского удостоверения производится по результатам проведения экзаменов: теоретического экзамена и практического экзамена экзамен по первоначальным навыкам управления транспортным средством и экзамен по управлению транспортным средством в условиях дорожного движения - на категории «B», «C», «D», «BE», «CE» и «DE» и подкатегории «C1», «D1», «C1E» и «D1E». B случае наличия в иностранном национальном водительском удостоверении разрешающих отметок, подтверждающих наличие права управления транспортными средствами нескольких категорий и (или) подкатегорий, обмен иностранного национального водительского удостоверения производится по результатам проведения экзаменов на право управления высшей из имеющейся в иностранном национальном водительском удостоверении категории или подкатегории.
В случае наличия в иностранном национальном водительском удостоверении разрешающих отметок, подтверждающих наличие права управления отдельными видами составов транспортных средств, обмен иностранного национального водительского удостоверения производится по результатам проведения экзаменов на право управления составом транспортных средств высшей из имеющейся в иностранном национальном водительском удостоверении категории или подкатегории.

Для обмена иностранного национального водительского удостоверения предоставляются следующие документы: а) заявление; б) паспорт или иной документ, удостоверяющий личность; в) медицинское заключение; г) иностранное национальное водительское удостоверение.

Обмен иностранных национальных водительских удостоверений сотрудникам дипломатических представительств и консульских учреждений иностранных государств в Российской Федерации и членам их семей, сотрудникам международных организаций и их представительств, аккредитованных при Министерстве иностранных дел Российской Федерации, и членам их семей, имеющим дипломатические, консульские, служебные карточки или удостоверения, выданные указанным Министерством, производится без проведения экзаменов и без предъявления медицинского заключения.

Иностранные национальные и международные водительские удостоверения, не соответствующие требованиям международных договоров Российской Федерации в области обеспечения безопасности дорожного движения, обмену на российские национальные и международные водительские удостоверения не подлежат.

Выдача российских национальных и международных водительских удостоверений взамен утраченных (похищенных) 
иностранных национальных и международных водительских удостоверений, выданных в других государствах, не производится.

Иностранное национальное водительское удостоверение, на основании которого выдано российское национальное водительское удостоверение, возвращается его владельцу.

К примеру, если 1 июня 2015 года сотрудник Госавтоинспекции остановит маршрутную ГАЗЕЛЬ и увидит, что у водителя-иностранца нет российского водительского удостоверения, и он осуществляет поездку в рамках трудовой или коммерческой деятельности, то этому водителю-иностранцу грозит административный штраф в размере от пяти до пятнадцати тысяч рублей за управление транспортным средством без права на управление согласно части 1 ст. 12.7 КоАП РФ, при этом водителя отстранят от управления автомобилем согласно части 1 ст. 27.12 КоАП РФ. Одновременно с этим подвергается административному наказанию в виде административного штрафра в размере пятидесяти тысяч рублей ответственное лицо, допустившее к управлению транспортным средством водителя-иностранца, не имеющего российского национального водительского удостоверения к управлению транспортным средством.

Этот запрет не коснется тех водителей-иностранцев, которые управляют транспортным средством, участвующим в международном движении, и у которых есть для этого специальное разрешение.

В соответствии с Федеральным законом от 30 декабря 2001 г. № 195-Ф3 «Кодексом Российской Федерации об административных правонарушениях» иностранные граждане, лица без гражданства и иностранные юридические лица, совершившие на территории Российской Федерации административные правона- рушения, подлежат административной ответственности на общих основаниях.

Столь жесткие меры в отношении найма иностранных водителей появились не просто так. Изначально законодателей беспокоило количество аварий с участием водителей-иностранцев. По данным ГУОБДД МВД России, за первое полугодие 2014 г. иностранные водители на дорогах России совершили почти 700 тысяч нарушений правил дорожного движения, а за весь 2013 год иностранцев оштрафовали более 1 миллиона раз ${ }^{[4]}$. Таким образом, столь жесткий подход законодателя представляется совершенно справедливым.

Говоря о мерах административного принуждения, направленных на удаление иностранного гражданина или лица без гражданства за пределы Российской Федерации, нельзя не упомянуть о таком специфическом методе административно-правового регулирования, как институт нежелательности пребывания (проживания) иностранного гражданина или лица без гражданства в Российской Федерации. Этот метод является одним из эффрективных средств миграционной политики России. Основное отличие от депортации и административного выдворения в том, что на принятие такого решения не влияет сам факт нахождения иностранного гражданина или лица без гражданства на территории Российской Федерации. Его основанием является сама возможность (угроза) въезда и пребывания иностранного гражданина (лица без гражданства) на территории Российской Федерации. Депортация является лишь обеспечительной мерой воздействия по отношению к исполнению решения о нежелательности пребывания (проживания) иностранного гражданина или лица без гражданства в Российской Федерации. Правом принятия решения о

${ }^{4}$ Cайт http://www.gibdd.ru. (Дата обращения 17.11.2014 г.). 
нежелательности пребывания (проживания) иностранного гражданина или лица без гражданства в Российской Федерации обладают МВД России, ФСБ России, Минобороны России, Минздравсоцразвитие России, Минюст России, МИД России, ФМС России.

Следует отметить, что указанная мера находится на стыке соприкосновения различных областей государственной политики: экономической безопасности, социальной безопасности, военной безопасности, транспортной безопасности и других.

В соответствии со статьей 26 Федерального закона от 15 августа 1996 г. № 114-Ф3 «О порядке выезда из Российской Федерации и въезда в Российскую Федерацию» иностранному гражданину (лицу без гражданства) въезд в Российскую Федерацию может быть запрещен в случае, если он на территории Российской Федерации два и более раза привлекался к административной ответственности, в том числе за нарушение ПДД, а также в случае неуплаты административного штрафра за допущенные нарушения. Данная норма права нашла свое отражение в приказе МВД России от 10 ноября 2012 г. № 1024 «О порядке представления и рассмотрения в МВД России и его территориальных органах материалов для принятия решения о нежелательности пребывания (проживания) иностранного гражданина или лица без гражданства в Российской Федерации» .

Необходимо сказать, что сорера административного воздействия на иностранных граждан и лиц без гражданства, нарушивших законодательство Российской Федерации, является, пожалуй, одной из самых уязвимых, поскольку призвана воздействовать на субъект транспортной инфраструктуры, чье поведение характеризуется нарушением правовой нормы, путем ограничения их прав и свобод. Поэтому регулирование данной сореры общественных отношений должно быть наиболее подробно регламентировано и не должно допускать каких-либо отступлений от принципов права.

Завершая исследование административно-правового статуса участников дорожного движения (иностранных граждан и лиц без гражданства), необходимо отметить, что правовое регулирование данного института нельзя назвать совершенным. Между тем законодатель устанавливает достаточно подробное регулирование данного правового института в Федеральном законе от 9 февраля 2007 года № 16-Ф3 «О транспортной безопасности», в Федеральном законе от 25 июля 2002 г. № 115-Ф3 «О правовом положении иностранных граждан в Российской Федерации», в Федеральном законе от 10 декабря 1995 года № 196-Ф3 «О безопасности дорожного движения», в Федеральном законе от 15 августа 1996 г. № 114-Ф3 «О порядке выезда из Российской Федерации и въезда в Российскую Федерацию», в Федеральном законе от 30 декабря 2001 г. № 195-Ф3 «Кодекс Российской Федерации об административных правонарушениях», в постановлении Совета Министров - Правительства Российской Федерации от 23 октября 1993 г. № 1090 «О правилах дорожного движения», в постановлении Правительства Российской Федерации от 24 октября 2014 г. № 1097 «О допуске к управлению транспортными средствами».

Достаточно подробно регламентирован в настоящее время порядок въезда в Российскую Федерацию и выезда из Российской Федерации иностранных граждан и лиц без гражданства. Между тем необходимо постоянно совершенствовать систему учета (совершенных административных правонарушений, в том числе дорожно-транспортных происшествий, не оплаченных административных штрафов, преступлений, выдан- 
ных водительских удостоверений и т.д.) подобной категории лиц, как в целях защиты безопасности и конституционного строя Российской Федерации.

Отдельной проблемой административно-правового статуса участников дорожного движения (иностранных граждан и лиц без гражданства) является привлечение их к административной ответственности и исполнение административных наказаний.

По словам Заместителя Министра внутренних дел Российской Федерации генерал-полковника полиции Виктора Николаевича Кирьянова, Россия подписала несколько соглашений, согласно которым страныучастницы будут обмениваться данными по поводу нарушений ПДД, на данный момент предложение поддержали Белоруссия, Армения, Казахстан, Киргизия и Таджикистан. «С каждым государством подписывается отдельное соглашение, мы эту работу начали. Мы готовы сотрудничать со всеми странами, но пока процесс идет тяжело» ${ }^{[5]}$. Совершенствование административно-правового статуса участников дорожного движения - (иностранными гражданами и лицами без гражданства) имеет не только политическое, организационное, социально-экономическое, правовое, информационное, но и правоохранительное значение, оказывает позитивное влияние на государственную политику в области обеспечения безопасности, в том числе его авторитета как правового государства на международной арене, но и самое, по нашему мнению главное: дает реальную возможность снизить количество нарушений правил дорожного движения и уменьшить количество дорожно-транспортных происшествий с участие иностранных граждан и лиц без гражданства.

\section{Библиография:}

1. Костенников М. В., Куракин А. В. Актуальные проблемы административного права. - М., 2013.

2. Сизов И.Ю. Административно-правовое взаимодействие органов внутренних дел в соере обеспечения правового статуса иностранных граждан. // Полицейская деятельность. - 2011. - 2. - C. $24-30$.

\section{References (transliterated):}

1. Kostennikov M. V., Kurakin A. V. Aktual'nye problemy administrativnogo prava. - M., 2013.

2. Sizov I.Yu. Administrativno-pravovoe vzaimodeistvie organov vnutrennikh del v sfere obespecheniya pravovogo statusa inostrannykh grazhdan. // Politseiskaya deyatel'nost'. - 2011. - 2. - C. $24-30$. 
На основании, приказа МВД России от 10 ноября 2012 г. № 1024, предложен алгоритм действий сотрудников полиции о порядке представления и рассмотрения в МВД России и его территориальные органы материалов для принятия решения о нежелательности пребывания (проживания) иностранного гражданина или лица без гражданства в Российской Федерации.

Необходимо:

1. Произвести выборку иностранных граждан, неоднократно в течение года привлекавшихся к административной ответственности в системе ТРИС РВ ГИБДД «Адмпрактика» ${ }^{[6]}$, которые фактически в настоящее время пребывают на территории Российской Федерации.

2. Получить сведения об отсутствии гражданства Российской Федерации у лиц, допустивших наибольшее количество административных правонарушений из адресного бюро.

3. В случае, если по адресному бюро указанные лица не значатся направить запрос в территориальные подразделения УФМС России.

4. Подготовить запрос в УФМС России по области (краю, республики) об осуществлении проверки иностранного гражданина по базе данных автоматизированной системы «ЦБДУИГ» ${ }^{[7]}$ (гражданство, законность нахождения на территории Российской Федерации, наличие правонарушений и т.д.).

5. Подготовить запросы в соответствующие территориальные подразделения УФМС России по области (краю, республики) о предоставлении копий иностранного паспорта; миграционной карты; уведомления о постановке на миграционный учет по месту пребывания.

6. Направить требование в ИЦ УМВД России по области (краю, республики) о привлечении указанных граждан в течение одного года к административной ответственности, а также о наличии неснятой или непогашенной судимости за совершение умышленного преступления на территории Российской Федерации или за ее пределами, признаваемого таковым в соответствии с Федеральным законом или сделать заверенную распечатку из базы «ИБДР» ${ }^{[8]}$.

7. Направить запросы в территориальные подразделения Госавтоинспекции о предоставлении заверенных надлежащим образом копий постановлений по делам об административных правонарушениях, копий сопроводительных писем о направлении постановлений в службу ФССП России.

8. Истребовать в соответствующих подразделениях ФССП России копии недостающих постановлений по делам об административных правонарушениях. Копии заверить.

9. Составить докладную записку на имя начальника УГИБДД МВД по области (краю, республики) об установлении обстоятельств, являющихся основанием к принятию решения о нежелательности пребывания. На докладной записке должна быть проставлена резолюция: «Подготовить проект ходатайства. Срок 10 дней».

10. При поступлении материалов подготовить проект ходатайства о принятии решения о нежелательности пребывания (проживания) указанных иностранных граждан в соответствии с требованиями приказа МВД России от 10 ноября 2012 г. № 1024 и сопроводительное письмо на имя Заместителя Министра внутренних дел Российской Федерации генерала-полковника полиции В. Н. Кирьянова.

11. Согласовать проект ходатайства с начальником УГИБДД МВД по (краю, республики), заместителем начальника УМВД по области спублики) (по охране общественного порядка), референтом УДИР, правовым отделом, начальником полиции МВД по области (краю, республики).

${ }^{6}$ ТРИС ГИБДД «Адмпрактика» - Территориально-распределенная информационная система реального времени ТРИС РВ ГИБДД МВД России.

7 «ЦБДУИГ»- Центральный банк данных по учету иностранных граждан и лиц без гражданства, временно пребывающих и временно или постоянно проживающих в Российской Федерации.

8 «ИБДР»- информационная база данных регионального уровня. 
12. После подписания ходатайства поставить гербовые печати в 2 местах.

13. Все прилагаемые к ходатайствам документы должны быть заверены должностным лицом УГИБДД МВД по области (краю, республики) и печатью.

14. После направления материалов осуществлять контроль за их прохождением в ГУОБДД МВД России.

15. По получении информации ГУОБДД МВД России о подписании ходатайства подготовить проект уведомления, вписав в него реквизиты принятого МВД решения и направить на подпись начальнику УМВД по области (краю, республики).

16. По получении решений о нежелательности пребывания из МВД России в течение 7 дней ознакомить граждан.

17. Направить копии решений, уведомлений, а также имеющиеся сведения о месте пребывания (проживания) иностранного гражданина в УФМС России по республики) для осуществления контроля за выездом из Российской Федерации. области (краю, 